Canadian University Music Review

Revue de musique des universités canadiennes

\title{
Characterizing Rock Music Cultures: The Case of Heavy Metal
}

\section{Will Straw}

Numéro 5, 1984

URI : https://id.erudit.org/iderudit/1013933ar

DOI : https://doi.org/10.7202/1013933ar

Aller au sommaire du numéro

Éditeur(s)

Canadian University Music Society / Société de musique des universités

canadiennes

ISSN

0710-0353 (imprimé)

2291-2436 (numérique)

Découvrir la revue

Citer cet article

Straw, W. (1984). Characterizing Rock Music Cultures: The Case of Heavy Metal. Canadian University Music Review / Revue de musique des universités

canadiennes, (5), 104-122. https://doi.org/10.7202/1013933ar

All Rights Reserved (C Canadian University Music Society / Société de musique des universités canadiennes, 1984
Ce document est protégé par la loi sur le droit d'auteur. L'utilisation des services d'Érudit (y compris la reproduction) est assujettie à sa politique d'utilisation que vous pouvez consulter en ligne.

https://apropos.erudit.org/fr/usagers/politique-dutilisation/ 


\title{
CHARACTERIZING ROCK MUSIC CULTURES: THE CASE OF HEAVY METAL
}

\author{
Will Straw
}

\section{INTRODUCTION}

One of the questions central to the sociology of popular music at the moment concerns the applicability of subcultural theory, developed principally in Great Britain, to the study of North American rock music culture(s). While it may be observed that Amerícan academic writing on rock music places considerable emphasis on the institutions producing and disseminating it, and that British research has focussed primarily on the processes of consumption and appropriation carried out by audiences, the extent to which this divergence is the product of differences between North American and British rock cultures remains a point of contention.

The issue is further complicated by specific characteristics of North American rock culture in the 1970s, between the decomposition of the hippy-psychedelic counter-culture and the limited emergence of punk and post-punk cultural formations near the end of that decade. Should this period, as is sometimes argued, be regarded as one in which institutional-economic imperatives resulted in the recuperation and dissolution of sub-cultural activity surrounding rock music? If so, the relative validity of sub-cultural or institutional-manipulative forms of explanation (what might be crudely termed bottom-up and top-down models, respectively) becomes a question of transitory pertinence, rather than the stake in more general debates over the nature of rock music processes as a whole. One can suggest, for example, that Hirsch's cyclical account of rock music's history, which distinguishes between periods of industry turbulence and periods of re-oligopolization, ${ }^{1}$ may be seen as 
differentiating those periods for which subcultural models and institutional-economic explanations are most appropriate (see Hirsch 1972). The obvious problem here, however, is one of conceptual consistency: notions of audience practice, modes of subjective involvement and the very "meaning" of rock music are sufficiently fundamental to an epistemology of the sociology of rock music that they themselves should not change substantively with each generic current or period analyzed.

In this paper, I seek to incorporate observations and hypotheses concerning the consumption of music within the characterization of a specific "genre" within rock music-that of Heavy Metal.2 My point of departure is the argument that Heavy Metal audiences in the 1970s manifested certain regularities arising from their position within rock culture, and within a network of institutions and discourses constitutive of this culture. A consistent emphasis of this paper is the ways in which information and knowledge about rock music circulate within Heavy Metal audiences. I have chosen Heavy Metal because it seemed to me to constitute the locus of a number of tendencies characteristic of rock culture in North America in the 1970s.

The discussion that follows is organized around a number of principles of description and classification which seem necessary to the characterization of any current within rock music culture. In adopting this procedure, rather than the search for an explanatory key which would reduce Heavy Metal to a particular ideological function or outgrowth of audience predicament, I am aware that I run the risk of a simple descriptivism. Nevertheless, given the frequent tendency of the sociology of music to reduce instances of popular music to simple manifestations of more general cultural processes, a turn toward some level of descriptive detail seems at least a useful corrective.

\section{HEAVY METAL: STYLISTIC DERIVATION AND INSTITUTIONAL DISSEMINATION}

In discussing Heavy Metal music, and rock music of the 1970s more generally, I am interested primarily in North American rock culture, though a significant feature of that culture is its assimilation of British rock music. I suspect that certain features of British rock culture, primarily those arising 
out of radio programming policies, have made the dissemination of Heavy Metal in the United Kingdom different in significant ways from the forms it has taken in North America. Differences between the United States and Canada, however, would seem to be negligible.

\section{1) Genealogies of Style}

At one level, linear, genealogical explanations of music style possess a clear theoretical inadequacy, carrying, as they inevitably do, resonances of origin-as-explanation. Nevertheless, an attention to the intricate patterns of influence and crossfertilization between and within generic currents seems an essential component of a theory of musical meaning, if it is to avoid grounding that meaning in intrinsic, formal qualities of the musical text. It is the relationship of newly-emergent stylistic and structural features to the background of conventions against which these appear, that determines in large part the way in which a new song, album, or genre will be heard. Likewise, it is the shifting coalitions of different stylistic currents, and the institutional boundaries (radio formats, record label divisions, etc.) which seek to regularize these, that constitute the history of popular musical styles.

Heavy Metal has genealogical links with psychedelic rock, and can be said to have emerged as the hard edge of the latter (see Bangs 1976: 302). The decomposition of psychedelic music, in the late 1960s, followed three principal directions. The first of these, in the United States, involved a return to traditional, rural musical styles, with the emergence of country-rock, the best-known examples being the stylistic changes in the careers of The Byrds (in 1968) and The Grateful Dead (in 1970). In Great Britain and Europe, a second tendency took the form of a very eclectic reworking of traditional and symphonic musical forms within an electric or electronic rock context, with groups such as King Crimson, Jethro Tull, Genesis, and, to a lesser extent, the early Traffic and Soft Machine. The baroque-folk of such artists as Scott Walker and Donovan was a significant transitional moment in the emergence of this second current. The other major orientation, which may be found in both British and North American rock music of this period, was that towards the Heavy Metal style, frequently based in the chord structures of boogie blues, but retaining from psychedelia an emphasis on technological effect and instrumental virtuosity. 
A number of characteristics of rock group formats and performance styles in the late 1960s were important in the transition into Heavy Metal: the cult of the lead guitarist, the "power trio" and other indices of the emphasis on virtuosity, the "supergroup" phenomena, and the importance in performance of extended solo playing and a disregard for the temporal limits of the pop song. In groups on the periphery of psychedelia (such as Blue Cheer, Iron Butterfly, and The Yardbirds), many of the stylistic traits that would become dominant within Heavy Metal are in evidence. This relative coherence would be reinforced, through the 1970s, by the sedimentation of other stylistic attributes (those associated with stage shows, albumcover design, and audience dress and life-style patterns) and relatively long-lived sites of institutional support (radio formats, touring circuits, record industry structures, etc.).

\section{2) Institutions and Industries in the Early 1970s}

It may be said that the historical situation in which Heavy Metal music came to prominence was one in which institutions associated with the psychedelic period were either disappearing, or being assimilated within larger structures as part of widespread changes within the music-related industries. The overriding tendency in these changes was the diminishing of the role of a variety of classes of local entrepreneurs in the processes by which music was developed and disseminated. The institutions in question include free-form radio, a large number of independent record labels, the ballroom performance circuit, and the underground press, all of which had contributed, at least initially, to a high degree of regionalization within psychedelia and associated movements within rock music.

For a number of record industry analysts, the number of hit-making independent record labels is an index of the degree of "turbulence" within the industry. A consensus has emerged according to which, on this basis, the modern history of the American recording industry has been divided into three epochs: one running from 1940 to 1958 , marked by concentration and integration within and between the electronics, recording, and publishing industries; the 1959 to 1969 period, characterized by the "turbulence" associated with the introduction on a large scale of rock music; and, finally, the period which began in 1970, and which saw re-oligopolization to the extent that in 1979, the six largest corporations accounted for $86 \%$ of Billboard's 
total "chart action" (see Anderson et al. 1980: 41; Peterson \& Berger 1971; and Titus 1980). Two other statistics are worth noting: by the late 1960s, the album format had displaced the single as the dominant format in record sales, with $80 \%$ of dollars spent on records going for LPs in 1969 (see Chapple \& Garofalo 1980: 76 and Fornatele \& Mills 1980: 74); and, during the 1970s, in large part as a result of the overhead costs associated with oligopoly, the break-even point for album sales went from 20,000 to nearly 100,000 copies (see Taylor 1980: 298).

While this oligopolization of the American record industry in the 1970 s is undeniable, it is less certain that one can correlate with it the principles of functioning normally applied in the analysis of commodity production: specifically, the sequence oligopolization-bureaucratization-conservatism-standardization. Writers such as Paul Hirsch have argued that the centralization and bureaucratization of decision-making in the industries producing entertainment "texts" is rarely comparable to that found in other industries, and that entertainment institutions more closely resemble the house construction industry, with its organization of production along craft lines. Within the record industry, horizontal integration has frequently taken the form of the assimilation of smaller, specialized labels within conglomerates (through direct take-overs or production-distribution agreements), often in such a way that the positions of those involved in selection and production remain intact. The record industry in the 1970 s relied more on outside, contracted producers or production companies than it did earlier, in the days of the salaried artist and repertory director (see Hirsch 1972).

I would argue that a defining characteristic of much rock music production in the early 1970 s was its domination by rock elites, by people established in creative capacities within the industry. The supergroup phenomena of this period is symptomatic of this, as is the fact that most of the leading Heavy Metal bands (such as Humble Pie) were formed by remnants of groups popular in the 1960s. With exceptions, the country-rock and singer-songwriter genres which achieved high market penetration in the early 1970 s drew as well upon earlier groups or individuals who had been present within the industry within a variety of capacities (Randy Newman, Leon Russell, Carole King, members of the Eagles, etc.)

The implications of this situation for characterizations of the American record industry during these years are not obvious. 
The reliance on industry elites is symptomatic of industry conservatism insofar as it displaced most "street-level" talent hunting and might be seen as a resistance to innovation. However, this displaced, as well, traditional processes (in periods of "turbulence") whereby musicians with local followings and local entrepreneurial support first established themselves regionally, recorded for minor labels, proved their financial viability, and then were signed by majors. The latter now released records without this initial form of market-testing, a contributing factor in the increasingly high ratio of unprofitable to profitable records. The selection and development of talent and initiation of new styles became increasingly the activity of established creative personnel, and artist contracts common in this period of growth gave almost unprecedented control over the choice of producers and material (see Hirsch 1971: 384).

It is somewhat paradoxical, then, that in this period established creative personnel were depended upon and provided much of the innovation and stylistic change within rock music, given the high degree of oligopoly and vertical integration within the industry. It is clear, for example, that many of those formerly involved in support capacities (songwriters, session musicians, etc.) achieved star status because of the fluidity with which they could in this period move between or combine the production, composing, and performing functions, or with which members of groups could record albums. ${ }^{3}$ Moreover, this looseness of role definition, combined with the prosperity of both performers and the industry as a whole, encouraged the internationalization of record production, with, as one of its effects, the free movement of session personnel between Britain and North America and the emergence of eclectic cross-fertilizations of style.

If I stress these aspects of record industry functioning in the early 1970s, it is because the mutations of this period are a principle site over which two currents implicit within rock's historiography have battled. Much of the literature of the mid-to-late 1970s, describing industry growth in terms of the co-optation and destruction of the energies unleased in the 1960s, regards this period as exemplifying processes inevitable within mass or capitalist culture (see e.g., Chapple \& Garofalo 1980). It might be argued, however, that this period saw the triumph of craft production structures, in a sense that emphasizes degrees of artisanal control rather than the scale of the enter- 
prise. In this respect, the punk critique of early 1970s rock music -which focusses on its excesses and its eclecticism, rather than on an assumed standardization-is at the very least a necessary counterweight to those historical accounts which stress processes of recuperation.

The changes which occured in the programming policies of FM radio stations in North American between the late 1960s and mid-1970s are well-documented elsewhere, as is the decline of the local underground press (see e.g., Chapple \& Garofalo 1980; Fornatele \& Mills 1980; and Lampman 1980). In both cases, rising overhead costs and an increased reliance on large advertising accounts (with record companies prominent among these) grew out of and furthered the desire or need for expansion and integration. These processes contributed to the diminished attention to marginal or regional musical phenomena. Overhead costs and group performance fees were the major factors in the replacement of the mid-sized performance circuit by the large arena or stadium, a process that continued throughout the 1970 s, until the emergence of punk and new wave re-established the viability of certain classes of smaller venues.

It is clear that these developments led to increased standardization in FM radio and the rock press. The rise in radio playlist consultants, automated stations, and satellite-based networks were all significant elements in the evolution of FM radio throughout the 1970s. As well, the evolution of the rock press from local, subculturally based publications to national magazines is evident in the changes in Rolling Stone, one of the few to survive. I would argue, however, against seeing these developments as local examples of a more general trend toward standardization which would include the record industry as well. The new importance of radio playlist consultants was in part a response to the eclecticism and bulk of record company product and to the inability of individual stations, in most cases, to choose from among this product. More importantly, perhaps, the rigidity of formats grew out of demographic research concurrent with the widening of the rock audience to include a significant part of the actively-consuming population, and with the recessions of the 1970s which called for a more accurate targetting of listening groups (see Mooney 1980: 85). While demographic targetting would appear to remain a relatively minor aspect of record company strategies (except in the most general sense), it became crucial in shaping the formats of radio 
stations and magazines, two media based on the delivery of audiences to advertisers.

\section{3) Heavy Metal Audiences and Rock Institutions}

The processes described earlier as leading to the renewed importance of the national rock audience worked to constitute this as a "mass" audience in that the media disseminating rock music or information about it (radio and the press) increasingly relied on formats applicable on a national basis, rather than on ties to local communities (or, in the case of radio specifically, on the popularity of local radio personalities). Equally important, in my opinion, is that these developments increased the importance of an audience segment that had been somewhat disenfranchized by movements within rock in the late 1960sthe suburban youth market. Throughout the 1970s this has constituted the principal constituency of Heavy Metal music, and of Album-Oriented Rock, the format adopted by FM stations that play it.

In stressing the geographic situation of Heavy Metal audiences, rather than their regional, ethnic, racial, or class basis, I am conscious of the fact that the latter have had wider currency and have possessed greater theoretical acceptability within the sociology of rock music. Nevertheless, I regard the place of audiences within North American habitation patterns as crucial in determining the relationship between music, those institutions which disseminate it, and life-styles in a more general sense. The hostilities of the late 1970s between Heavy Metal audiences and disco subcultures are indicative in this respect; the demographics of disco showed it to be dominated by blacks, Hispanics, gays, and young professionals, who shared little beyond living in inner urban areas (see Fornatele \& Mills 1980: 77).

Suburban life is incompatible for a number of reasons with attendance at clubs where one might hear records or live performers; its main sources of music are radio, retail chain record stores or departments (usually in shopping centers) and occasional large concerts (most frequently in the nearest arena). These institutions make up the network by which major label albums are promoted and sold, and from which music not available on such labels is for the most part excluded.

My argument is not that this institutional network gave major labels a free hand in shaping tastes, but that, in conjunction with suburban life-styles, it shaped the form of involvement 
in rock culture, discouraging subcultural activity of the degree and kind associated with, for example, disco or punk. Heavy Metal audiences may be characterized in part by the absence of a strong middle-strata between the listener and the professional group. Only in rare cases, within such audiences, could there be found an echelon of local Heavy Metal bands performing their own material in local venues. What I have referred to as the dominance of rock music during this period by elites, in conjunction with the overall decline in small-scale live performance activity in the early 1970s, worked to block the channels of career advancement characteristic of other stylistic currents or other periods within rock history. It might also be suggested that the economy of North American suburbs in most cases discourages the sorts of marginality that develop in large inner urban areas and render them appropriate to the fostering of musical subcultures. High rents and the virtual absence of enterprises not affiliated with corporate chains mean that venues for dancing or listening to live music are uncommon. If, for the purposes of this discussion, a musical subculture is defined as a group whose interaction centers to a high degree on sites of musical consumption, and within which there are complex gradations of professional or semi-professional involvement in music and a relative looseness of barriers between roles (such that members will all be involved, in varying degrees, in collecting, assessing, presenting, and performing music), then Heavy Metal audiences do not constitute a musical subculture.

\section{ROCK CULTURE: HISTORY/DISCOURSE/GENDER}

\section{1) Heavy Metal and the Discourses of Rock Culture}

Equally important to the characterization of Heavy Metal's place within rock culture was its relationship to what might be called the rock music "archive." A major attribute of Heavy Metal, I would argue, is its consistent non-invocation of histories or mythologies of rock music in any self-conscious sense. The iconography of Heavy Metal performances and album covers, and the specific reworking of boogie blues underlying the music, do not suggest the same modalized relationships to popular music history that country-rock, glitter-rock, and even disco (with its frequent play upon older motifs of urban show-business 
night-life) demonstrated. As well, there is nothing to suggest that Heavy Metal listeners regularly became interested in tracing the roots of certain musical traits back to periods prior to the emergence of Heavy Metal. While the terms "rock" and "rock and roll" recur within lyrics and album titles, this is almost always in reference to the actualities of the performance and the energies to be unleased therein, rather than to historical mythologies of rock music.

It may be argued that rock music culture exhibits a continuous tension between a discourse wherein is evident a modalized relationship to rock music's history and mythologies, and a discourse of authenticity and presence. The transformations of country-rock groups such as The Eagles or Poco from genre revivalists to purveyors of a mainstream eclecticism demonstrate one response to this tension, clearly shaped by commercial constraints. More recently, competing definitions of punk have likewise reflected this tension, some seeing in it a self-conscious minimalist reduction of rock song structures and other regarding it as the expression of raw energy.

The response of American rock criticism to Heavy Metal in the early-mid 1970 s was consistently a negative one. The increased reliance of rock criticism, such as that in Rolling Stone, on the terms of journalistic film criticism, resulted in its valuing fidelity to basic generic structures and links to the archive of American popular music. (The enormous enthusiasm accorded Bruce Springsteen is revealing in this respect.) The emphasis on the individual career or genre as the context within which records were evaluated accompanied the rise of the "serious" record review. These new emphases not only diminished the interest in Heavy Metal, to which these criteria were applicable only in very limited ways, but they made the audience a relatively minor focus of rock criticism, as the latter moved away from the pop-journalistic or counter-cultural concerns of a few years earlier.

These developments had two principal effects on Heavy Metal's place within the discourses of rock culture. On the one hand, critical dismissal frequently resulted in Heavy Metal musicians employing a discourse of populism, whose main tenet was that critics had lost touch with broad sections of the rock audience. On the other, this presented critics with the dilemma of responding negatively to a current within rock music without employing the terms traditionally used to condemn rock music 
overall (sameness, loudness, musical incompetence), or those with greater acceptability within rock culture, but inappropriate in this case (commercialism, standardization). Only Creem magazine was able, for a limited time, to construct a relatively coherent discourse which allowed for a qualifiedly positive response to certain types of Heavy Metal, primarily by placing these within a genealogy of bad-boy or punk-ish currents within rock history.

Accompanying this expulsion from the dominant value system of rock criticism, the lack of historiographical selfreferentiality, and the network of institutional supports described above, is the almost total lack of hobbyist activity surrounding Heavy Metal in the 1970s. Until recently, participation in Heavy Metal culture was not accompanied by record collecting on a large scale, the hunting down of rare records, the reading of music-oriented magazines, or high recognition of such things as record labels or producers. To the extent that a Heavy Metal archive existed, it consisted of albums from the 1970s on major labels, constantly in print, and easily available in chain record stores. There was thus little basis for the presence, within Heavy Metal audiences, of complex hierarchies based on familiarity with the music, possession of obscure records, or relationships of opinion leadership as determinants of taste and acquisition patterns. An infrastructure of importers, speciality stores, independent labels, and fanzines was almost non-existent in Heavy Metal culture during the early 1970s, and has emerged only to a limited extent in the $1980 \mathrm{~s}$.

In its distance, both from Top 40 culture, and from the mainstream of critical discourse on rock music, Heavy Metal in the 1970s was the current least marked by rock culture's usual processes of contextualization. It is still rarely the case, for example, that Heavy Metal cuts are played on the radio for their nostalgic or "oldies" value; they are presented implicitly as existing contemporaneously with recent material, with none of the transitory resonances of Top 40 or the contextualization within individual careers or genres which the rock press brings to bear upon other forms.

The specificity of Heavy Metal, in a sense, may be said to lie in the apparently paradoxical relationship between two of its principal attributes. On the one hand, as suggested, its audiences were not involved in the music in an intensely hobbyist fashion and they lacked most of the features of a musical subculture. 
At the same time, however, these audiences exhibit coherent and consistent taste patterns which distinguish them from the casual audiences for eclectic, trans-generic examples of rock music.

\section{2) Masculinity}

That the audience for Heavy Metal music is heavily male-dominated is generally acknowledged, and statistically confirmed. ${ }^{4}$ Clearly, the performers of Heavy Metal are almost exclusively male, recent exceptions such as Girlschool being accorded attention most often for their singularity. In this section, I tentatively explore two aspects of Heavy Metal's relationship to male gender styles: the place of its audiences within a limited typology of such styles, and the iconography that has come to surround this music.

Rock culture both offers and draws upon a variety of male gender styles, of which a limited number will be discussed here. A crucial determinant of such styles, I would argue, is the relationship between the possession of knowledge and the deployment of this knowledge within social interaction, the presentation of the physical body, and the construction of a stance as a gendered subject. The deployment of knowledge in the adoption or construction of a gender style may be called the "eroticization" of this knowledge, if by "eroticization" we designate a process whose significance is primarily internal to male peer cultures, and is not based to any great extent on measurable or observable effects produced in those to whom these styles or stances might be directed. Rock music culture, as a result of its significance within youth peer cultures overall, provides a privileged reservoir of knowledge suitable for deployment in these ways.

One of the problems in the study of Heavy Metal arises in attempting to reconcile the observation that heavy involvement in rock music-as a collector, reader of the rock press, etc. is primarily a male pursuit (see Frith \& McRobbie 1978/79) with the recognition that these activities are for the most part absent from the most "masculinist" of rock audiences, that surrounding Heavy Metal.

Within male youth culture, a strong investment in archivistic or hobbyist forms of knowledge is usually devalorized, marginalized as a component of what in North America is called "nerd" culture. This marginalization is not simply directed at 
intellectual or knowledgeable males; rather, it involves specific relationships between knowledge and the presentation of the physical body.

If, within a typology of male identity patterns, Heavy Metal listeners are in a relationship of polarity to "nerds," this is primarily because the former do not usually regard certain forms of knowledge-possession (particularly those derived from print media) as significant components of masculinity. Stated schematically, the "nerd" is distinguished by his inability to translate knowledge into socially-acceptable forms of competence, and more masculinist peer groupings (such as that constitutive of Heavy Metal culture) by their emphasis on competences demonstrable in social situations exclusively. Interestingly, neither of these groups is seen to partake of what the dominant discourse within rock culture has defined as "cool."

"Cool" may be said to involve the eroticization and stylization of knowledge through its assimilation within an imagery of competence, experience, and detachment. Increasingly, throughout the 1970s, the imagery of a wide range of Anglo-American rock performers (Lou Reed, David Bowie, Patty Smith, Iggy Pop, Bryan Ferry, etc.) based itself on the integration of street wisdom, a certain ironic invocation of rock mythology, and, in some cases, gender ambiguity (whose overriding significance was as an index of experience) within relatively coherent styles and physical stances. The recurrence of black leather, or of "rebel" postures in the iconography surrounding such music never resulted in its assimilation within the more masculinist tendencies within rock culture, since these motifs overlapped considerably with those of gay culture, or involved a significant degree of intellectualization (such as the use of "camp").

Since the mid-1970s, a current has emerged that occupies a position equidistant between the "cool" and "masculinist" stances described above, and which has been a central component of the FM rock mainstream. Bruce Springsteen, John Cougar, Bob Segar, and numerous others play on variants of a stance that has integrated both the "cool" inscription of a modalized relationship to rock history and mythology and the anthemic authenticity of presence whose fullest flowering occurs within Heavy Metal. What particularly serves to distinguish this hybrid from the more pure examples of "cool" is the relative absence in the former of androgynous motifs, and the celebration, within songs, of rituals of male peer group interaction (albeit with varying degrees of detachment). 
To the extent that rock culture in the 1970s possessed a "nerd" component, it emerged to a significant degree within the audiences for British symphonic or progressive rock (groups such as Genesis or Yes, before these achieved mainstream success). Progressive rock, until the late 1970s, fostered a hobbyist involvement among North American listeners and spawned a network of importers, specialty stores, and fanzines. An interest in British progressive rock has been correlated with the frequent reading of, and subcultural involvement in, science-fiction, another important component of one strand of "nerd" culture. ${ }^{6}$

The specificity of progressive rock culture may be defined by its divergence from both the masculinist stances surrounding Heavy Metal, and from the "cool" gender stances that existed during the 1970s. The iconography surrounding progressive rock was marked by its failure to engage, either with any mythologies surrounding rock music, or with the discourse on sexuality that was a major component of other rock cultures. While punk would choose the mythologies and iconographies of rock culture as the site of its intervention within sexual politics, progressive rock (in part as a result of its aspirations to respectability) consistently avoided this site.

\section{3) Iconography}

The major stylistic components of Heavy Metal iconography may be inventoried as follows: long hair for both performers and audiences, denim jackets and jeans among audiences, smoke bombs as an element of stage performances, and the taking of depressant drugs. On album covers, one finds an eclecticism near the beginning, but the gradual cohering of an inconography combining satanic imagery and motifs from heroic fantasy illustration. The remarkable aspect of traits such as long hair and denim jackets is their persistence and longevity within Heavy Metal culture, long after these had ceased to be fashionable across the wider spectrum of North American youth culture. Mention should be made, however, of the decadelong shift whereby these came to acquire connotations of low socio-economic status and masculinist values, in part through their differences from the stylistic features of gay and punk subcultures.

The satanic imagery which in the late 1970s came to dominate the iconography surrounding Heavy Metal may be 
seen as the development of certain tendencies present within psychedelia. It is known, for example, that within the hippy counter-culture fantasy literature such as Tolkien's Lord of the Rings was widely read and provided motifs for a wide range of examples of poster art, songs, album covers, and so on. In progressive rock of the 1970s, album covers by artists such as Roger Dean, which were commercialized in poster and book form, represented a continuation of this current. The iconography of Heavy Metal culture, as it became more coherent by middecade, grew out of one particular strand within this overall tendency: that of heroic fantasy literature and illustration, most closely associated with fictional characters such as Conan the Barbarian. Dominated by an imagery of carnage, and mildly pornographic, the illustrative style which emerged around Heavy Metal may be seen as a masculinization of the fantasy elements present within psychedelic culture.

As this iconography came to dominate within Heavy Metal culture there was a proliferation of fantasy and satanic imagery as elements of vehicle decor, pinball machine thematics, poster art, T-shirt and jean jacket illustration, and so on. For the most part, this tendency has involved the inscribing of a masculinistheroic element within the fantastic or mystical motifs that surrounded psychedelic and, later, progressive rock. These motifs increasingly stand out against the geometrical-minimalist and retro design principles that became widespread within rock music following the emergence of punk and new wave.

\section{CONCLUSION}

Heavy Metal is at once the most consistently successful form of rock music and the most marginalized within the discourse of institutionalized rock culture. That literary criticism is not regularly unsettled by the popularity of Harlequin Romances, while North American rock culture regards Heavy Metal as a "problem" is symptomatic of the tension in the 1970 s between the ascension of critical discourse on rock music to respectable institutional sites and the populist reading of rock music as an important underpinning of that discourse.

Heavy Metal in North America offers perhaps one of the purest examples of involvement in rock music as an activity subordinate to, rather than determinate of, peer group formation 
-one reason, perhaps, for the restriction of its appeal to limited age groups. While involvement in disco or punk very often determines choices as to the types or sites of interpersonal interaction, or even the selection of occupations or places to live, involvement in Heavy Metal, for the most part, does not.

In the last five years, both the nature and place of Heavy Metal have undergone a number of transformations. The following summary remarks, while by no means exhaustively characterizing Heavy Metal's more recent developments, should at least suggest directions for further research:

1. Following the cross-fertilizations at the beginning of the 1980s, which saw numerous hybrids of Heavy Metal and both symphonic and mainstream rock, 1984 has seen, in certain quarters, the resurgence of a new purism. The rise of independent labels disseminating Heavy Metal, and the new wave of British Heavy Metal bands, are indices of an emergent Heavy Metal subculture with more of the traditional features of rock music subcultures. At the same time, a return to a purist form of Heavy Metal has been promoted by Album-Oriented Rock consultants as one possible response to the crisis of AlbumOriented Rock radio.

2. The relationships of Heavy Metal to the new Top 40 mainstream constituted primarily around black-and-white dance music, has produced further retrenchment, as Heavy Metal is often proferred as the refuge of authenticity (and, implicitly, of masculinist values). Amid the shifting coalitions of mid1980 s rock genres, with the re-enfranchisement of young teenagers and females as significant forces in the music markets, Heavy Metal is often presented as anti-fashion, anti-commercial, and authentic. The fragmentation of post-punk, and movement of its dance components into the mainstream, has been such that much hard-core or neo-punk music now occupies a structural position similar to that of Heavy Metal vis-à-vis this mainstream. Each now represents an almost exclusively masculinist response to this mainstream, and profers a discourse of authenticity and anti-fashion. While a highly intellectualized hard-core avantgarde continues to develop, it must be noted that the level of female involvement one found at the time of punk's emergence has been lost.

3. Finally, mention should be made of the documentaryparody on Heavy Metal, This is Spinal Tap, an insightful 
cataloguing of many traits of Heavy Metal culture. Particularly perceptive, in my view, are such details as the debased, late1970s New Wave fashion motifs (skinny leather ties, leopardskin pants) adopted by the musicians in an apparent and inept concession to fashion, and the mystical component of Heavy Metal iconography, epitomized here in the group's use of a reconstructed Stonehenge as part of a stage show. 


\section{NOTES}

1. "Oligopoly" is a term drawn from economic analysis which refers to the control of an industry by a limited number of corporations.

2. I use the term "Heavy Metal" to designate those forms of music which the discourse of rock culture has come to call "Heavy Metal," without entering into complex discussion of the generic traits of this music. Clearly, the more this term has become accepted within rock culture, the more it has become the basis of the cohering of a number of iconographic, musical, and promotional styles, so that the existence of the term itself has been a factor in shaping the development of this music and the culture that surrounds it.

3. While the bases for comparison are limited, the American record industry in the 1970 s resembled in certain ways the American film industry following the anti-trust decisions of the 1940s which divorced the production and distribution entities from those involved in exhibition. In both cases, one finds a high reliance on licensing agreements between major companies and smaller production entities; in both cases, there is a fluidity of movement between occupational roles and a tendency (often tax-related) for stars to build corporate entities around themselves and work in a variety of international locales.

4. See, for a recent proof, "New Wave Beating Out Heavy Metal," Billboard, June 2, 1984; and, for a discussion of the demographics of Album-Oriented Rock radio, Fornatele \& Mills 1980: 74).

5. "Anthemic" is a term drawn from rock criticism; rock songs and performances are considered to be anthemic when they appear to express the concerns and impulses associated with youth culture.

6. The source for the demographic information on science-fiction reading and musical preferences is a personal interview in July 1981, with Len Mogel, publisher of Heavy Metal magazine. The link between subcultural involvement in science-fiction and "nerdishness" is no more absolute than are the definitions of these attributes, but is often commented upon within science-fiction fandom itself; my remarks are based on my reading of several hundred science-fiction fanzines from the 1970s. 


\section{REFERENCES}

ANDERSON, B., HESBACHER, P., ETZKORN, K.P., AND DENISOFF, R.S.

1980: "Hit Record Trends: 1940-1977," Journal of Communication, $\mathrm{XXX} / 2,31-43$.

BANGS, L.

1976: "Heavy Metal," in Miller, J., ed., The Rolling Stone Illustrated History of Rock and Roll. New York: Rolling Stone Press/Random House, 302-05.

CHAPPLE, S. and GAROFALO, R.

1980: Rock ' $n$ ' Roll is Here to Pay. Chicago: Nelson-Hall.

FORNATELE, P. and MILLS, J.

1980: Radio in the Television Age. Woodstock, N.Y.: Overlook Press.

FRITH, S. and McRobbie, A.

1978/79: "Rock and Sexuality," Screen Education, No. 29, 3-19. HIRSCH, P.

1971: "Sociological Approaches to the Pop Music Phenoemena," American Behavioral Scientist, XIV/3, 371-88.

1972: "Processing Fads and Fashions: An Organization-Set Analysis of Cultural Industry Systems," American Journal of Sociology, LXXVII/4, 639-59.

LAMPMAN, R.

1980: "The Metaphysics of Automated Rock Radio," Popular Music and Society, XII/3, 159-64.

MOONEY, $\mathrm{H}$.

1980: "Twilight of the Age o Aquarius? Popular Music in the 1970s," Popular Music and Society, VII/3, 182-98.

PETERSON, R. and BERGER, D.

1971: "Entrepreneurship in Organizations: Evidence from the Popular Music Industry," Administrative Science Quarterly, xVI/1, 97-107.

TAYLOR, S.

1980: "The Seventies," in Collins, J., ed., The Rock Primer. Harmondsworth, Middlesex: Penguin Books, 291-323.

TITUS, P.

1980: "The Rise and Fall of the First Album," New York Rocker, September, pp. 24-25. 